\title{
ESTUDO COMPARATIVO DO COMPORTAMENTO DA INFECÇÃO DE CAMUNDONGOS, ATRAVES DA INOCULAÇÃO SUBCUTÂNEA E INTRAPERITONEAL, UTILIZANDO-SE DUAS CEPAS DE TRYPANOSOMA CRUZI
}

Fernando Henriques Pinto* Rosa Domingues Ribeiro* Francisco Miguel Belda Neto** José Clóvis do Prado Júnior*

PINTO, F.H. et al. Estudo comparativo da infecção de camundongos, através da inoculação subcutânea e intraperitoneal, utilizando-se duas cepas do Trypanosona cruzi, hev. Saúde públ., S. Paulo. $20: 133-40,1986$.

RESUMO: Foram utilizados camundongos brancos, pesando em média $18 \mathrm{~g}$ e duas cepas de Trypanosoma cruzi, morfologicamente distintas: Y com predominância de formas sangiíneas delgadas e Bolívia com predomínio de formas largas. Os lotes de animais receberam $2 \times 10^{3}, 2 \times 10^{4}$ e $2 \times 10^{5}$ tripanossomos por animal e as vias de inoculação utilizadas foram a intraperitoneal e a subcutânea. Nos animais foi observado o curso de infecção. Os resultados obtidos revelaram que, nos experimentos em que se utilizou a cepa $Y$, existem algumas diferenças significantes, com infecçōes mais uniformes e virulentas, após inoculação subcutânea de $2 \times 10^{3}$ e $2 \times 10^{4}$ formas sangüineas de $T$. cruzi. Entretanto, isto não ocorreu com a cepa Bolívia, pois os animais apresentaram o mesmo padrão de parasitemia e os demais caracteres morfológicos, quer se utilizasse a via subcutânea ou intraperitoneal. Tal fato permite sugerir a existência de interrelação entre os fatores via de inoculação traduzida pela maior ou menor presença de macrófagos no sítio de inoculação, e a morfologia das formas sangüíneas representada pela maior ou menor capacidade de penetração celular.

UNITERMOS: Trypanosoma cruzi. Camundongos, infecçāo experimental. Macrófagos, parasitologia. Infecçōes subcutâneas. Injeções intraperitoneais.

\section{INTRODUÇÃO}

Os resultados obtidos nas tentativas de correlação entre o polimorfismo do Trypanosoma cruzi e o seu comportamento biológico têm sido escassos. Essas dificuldades aumentam ainda mais, quando se tenta correlacionar os dados morfológicos das amostras com as suas ações patogênicas e respectivos quadros clínicos, tanto no homem como em animais de experimentação (Ferriolli Filho e col. ${ }^{12}$, 1968; Andrade e col. ${ }^{2}$, 1970; Belda Neto $^{3}, 1974$ ). Coura e col..$^{10}$ (1966) proprõem o uso da expressão "complexo cru$z i$ " para definir o comportamento das amostras do $T$. cruzi, tal a complexidade do problema.
A presença de tripomastigotas sangüícolas com diferentes morfologias já havia sido assinalada por Chagas ${ }^{\theta}$ (1909), que atribuiu ao fenômeno um significado de dimorfismo sexual. Brener e Chiari ${ }^{8}$ (1963) e Brener ` (1965) estudaram várias cepas de $T$. cruzi e mostraram que, em algumas populações, as formas delgadas predominam durante todo o curso da infecção experimental, ao passo que, em cutras, as formas delgadas constituem a Inaioria nos primeiros dias da infecção, sendo gradualmente substituídas por formas largas que passam a constituir mais de $90 \%$ da população. Essa diferente distribuição das formas permitiu estudar

- Do Departamento de Ciências da Saúde da Faculdade de Ciências Farmacêuticas de Ribeirảo Preto da Universidade de São Paulo - Av do Café s/n. $0^{\circ}-14100-$ Ribeirão Preto, SP - Brasil. - Do Departamento de Ciências Bio-Clínicas da Faculdade de Ciências Farmacêticas de Araraquara da Universidade Estadual Júlio de Mesquita Filho - Rua Expedicionários do Brasil. 1621 - 14800 - Araraquara, SP - Brasil. 
PINTO, F.H. et al. Estudo comparativo da infecção de camundongos, através da inoculação subcutânea e intraperitoneal, utilizando-se duas cepas do Trypanosoma cruzi. Rev. Saúde púbı, S. Paulo, 20: 133-40, 1986.

presumíveis diferenças fisiológicas entre os parasitas. Assim, quando tripomatigotas sangüíneos são inoculados endovenosamente em camundongos normais, as formas delgadas desaparecem rapidamente da circulação para cumprirem seu ciclo celular, ao passo que as formas largas continuam circulando por alguns dias sem serem tomadas por células do hospedeiro (Brener ${ }^{6}, 1969$ ).

E fato conhecido que macrófagos normais são frequientemente parasitados pelo $T$. cruzi no vertebrado e propiciam ao parasita um ciclo normal de evolução. Kierszenbaum e col. ${ }^{14}$ (1974), entretanto, inocularam formas sanguiíneas do $T$. cru$z i$ intraperitonealmente em camundongos e observaram que, quer nos macrófagos que eram retirados da cavidade peritoneal a intervalos regulares, quer naqueles retirados logo após a infecção e mantidos "in vitro", havia uma crescente destruição de parasitas fagocitados. Esses dados são indicativos de que, mesmo em animais normais, não imunizados, os macrófagos estariam envolvidos na resistência. Dvorak e Schmunis ${ }^{11}$ (1972) foram ainda mais longe ao demonstrar que tripomastigotas obtidos de cultura de tecido não se multiplicam nem sobrevivem em macrófagos peritoneais infectados "in vitro". Esses achados contrastam com experiências de outros autores (Hoff ${ }^{13}, 1975$ e Nogueira e Cohn ${ }^{17}$, 1976) que, em condições semelhantes, cultivaram sem problemas o parasita em macrófagos normais "in vitro", e também entram em aparente desacordo com as observações clássicas da literatura, nas quais as células do sistema fagocitário mononuclear são consideradas como particularmente adequadas ao parasitismo pelo $T$. cruzi.

Neal e MacHardy ${ }^{16}$ (1977) realizando estudos comparativos da infectividade do $T$. cruzi para camundongos utilizaram a via intraperitoneal e a via subcutânea de inoculação, concluindo que, infecções mais uniformes e virulentas são obtidas após inoculações subcutâneas. Segundo os autores, isto se deve principalmente à resposta celular imediata, nas inoculações intraperitoneais, ou seja, maior quantidade de macrófagos na cavidade peritoneal, já no momento da inoculação do parasita.

A proposição foi a de se realizar um estudo comparativo entre as duas vias de inoculação, intraperitoneal e subcutânea, utilizando-se no trabalho duas amostras do $T$. cruzi, morfologicamente distintas, na tentativa de completar e ampliar os resultados obtidos por Neal e MacHardy ${ }^{16}$ (1977). E possível que essas diferenças sejam apenas aparentes e que na realidade dependam de vários fatores, além do hospedeiro, como a amostra do parasita e a forma parasitária a ser fagocitada.

\section{MATERIAL E MÉTODO}

\section{Animais}

Foram utilizados camundongos albinos, de ambos os sexos pesando em média $18 \mathrm{~g}$, criados no Biotério do Campus de Ribeirão Preto.

\section{Cepas de Trypanosoma cruzi}

Foram utilizadas duas cepas do T. cru$z i$ : a cepa Bolívia, de características polimórficas, com formas sanguícolas predominantemente largas, isoladas de exemplares de Triatoma infestans capturados em domícilio, provenientes de Vitichi na Bolívia e que vem sendo mantida por repiques sucessivos, cada 14 dias em camundongos; e a cepa $\mathrm{Y}$ do tripanossomo, com predominância de formas delgadas, isolada de um caso humano de doença de Chagas por Silva e Nussenzweig ${ }^{20}$ (1953) e vem sendo mantida por repiques semanais, em camundongos.

Inoculação de animais com tripomastigotas sangüineos 
PINTO, F.H, et al. Estudo comparativo da infecção de camundongos, através da inoculação subcutânea e intraperitoneal, utilizando-se duas cepas do Trypanosoma cruzi. Rev. Saúde públ., S. Paulo, 20: 133-40, 1986.

Os tripomastigotas foram obtidos de doadores na fase aguda da infecção. $O$ inóculo era feito com sangue coletado através de punção cardíaca e recebido em anti-coagulante (Liquemine). Para padronização do inóculo, 3 amostras de aproximadamente $5 \mathrm{~mm}^{3}$ cada eram coletadas com pipeta de hemoglobina, examinadas entre lâmina e lamínula $(22 \times 22$ $\mathrm{mm}$ ) e o número de parasitas avaliado segundo técnicas de Brener ${ }^{4}$ (1962). As diluições foram feitas com salina tamponada, de tal modo que cada camundongo recebesse $0,1 \mathrm{ml}$ do inóculo.

Foram inoculados lotes de 30 camundongos e as vias utilizadas foram a subcutânea e a intraperitoneal. Cada animal recebeu inóculo de $2 \times 10^{3}, 2 \times 10^{4}$ e $2 \times 10^{5}$ tripomastigotas sangüíneos.

Nos animais foi observado o comportamento das cepas no que se refere ao índice de infecção, período pré-patente, parasitemia, duração da fase aguda e taxa de letalidade. Logo após a inoculação, os animais foram examinados diariamente e, depois da detecção do parasita, foram realizadas parasitemias, a cada dois dias, através da técnica de Brener ${ }^{4}$ (1962).

\section{RESULTADOS}

Durante o desenvolvimento do trabalho, foram realizados esfregaços de sangue de camundongos, ao acaso, no decurso da infecção e foi observado que a morfologia dos tripomastigotas sanguíneos se manteve, para as duas cepas, de forma análoga a inicial, independente da via de inoculação utilizada.

Os resultados obtidos, no que se refere aos caracteres da infecção de camundongos inoculados com formas sanguícolas das cepas $\mathrm{Y}$ e Bolívia do $T$. cruzi, através das vias subcutânea e intraperitonial, são apresentados nas Tabelas 1 a 3 .

$O$ exame da Tabela 1 revela que, nos animais inoculados com $2 \times 10^{3}$ parasitas da cepa $Y$, o índice de infecção foi de $100 \%$ quer se utilizasse a via intraperitoneal ou a subcutânea. O período pré-patente variou de 3 a 5 dias, com média de 3,76 dias para os inoculados via subcutânea e de 3,96 dias para os inoculados pela via intraperitoneal.

$\mathrm{O}$ número de tripanossomos, embora variável mesmo entre os animais de um dado lote, mostrou-se relativamente mais

TABELA 1

Caracteres gerais da infecção das cepas $\mathrm{Y}$ e Bolívia, através das vias subcutâneas e intraperitoneal, em camundongos inoculados com $2 \times 10^{3}$ formas sangüíneas do $T$. cruzi.

\begin{tabular}{|c|c|c|c|c|c|c|c|c|}
\hline \multirow{2}{*}{$\begin{array}{l}\text { Caracteres } \\
\text { da } \\
\text { Cepa/ infecção } \\
\text { via } \\
\text { Incculação }\end{array}$} & \multirow[t]{2}{*}{$\begin{array}{c}\% \\
\text { de } \\
\text { infecção }\end{array}$} & \multicolumn{3}{|c|}{$\begin{array}{l}\text { Período } \\
\text { pré-patente }\end{array}$} & \multicolumn{2}{|c|}{$\begin{array}{c}\text { Limites } \\
\text { da variação } \\
\text { Parasitemia }\end{array}$} & \multirow[t]{2}{*}{$\begin{array}{c}\text { Duração } \\
\text { da } \\
\text { fase aguda }\end{array}$} & \multirow[t]{2}{*}{$\begin{array}{c}\text { Taxa } \\
\text { de } \\
\text { letalidade }\end{array}$} \\
\hline & & Min & Máx & Méd. & $\mathrm{N} 9 / \mathrm{mm}^{3}$ & Dia & & \\
\hline Y Sub. & 100,0 & 3 & 5 & 3,76 & $959-2.947$ & $89-109$ & $(-)$ & $100,0 \%$ \\
\hline Y Intrap. & 100,0 & 3 & 5 & 3,76 & $749-2.807$ & $99-139$ & $15-21$ & $70,0 \%$ \\
\hline B. Sub. & 100,0 & 2 & 4 & 3,03 & $2.436-8.855$ & $179-219$ & $22-31$ & $43,3 \%$ \\
\hline B. Intrap. & 100,0 & 2 & 4 & 2,86 & $2,436-8,650$ & 179.219 & $25-30$ & $40,0 \%$ \\
\hline
\end{tabular}

(-) Indeterminada 
PINTO, F.H. et al. Estudo comparativo da infecção de camundongos, através da inoculação subcutânea e intraperitoneal, utilizando-se duas cepas do Trypanosoma cruzi. Rev. Saúde públ.. S. Paulo, 20: 133-40, 1986 .

elevado nos camundongos (Tabela 1), e o acme da parasitemia, nesses animais, foi atingido um pouco mais precocemente $\left(8 .^{\circ}\right.$ ao $12 .^{\circ}$ dia) do que nos inoculados pela via intraperitoneal $\left(9 .^{\circ}\right.$ ao $13 .^{\circ}$ dia). Todos os camundongos inoculados através da via subcutânea vieram a morrer. Releva notar que a morte sobreveio entre $013 .^{\circ}$ e $21 .^{\circ} \mathrm{dia}$, quando a parasitemia se achava numa segunda fase ascensional ou quando a parasitemia já se encontrava em declínio.

Dos animais inoculados pela via intraperitoneal, nove superaram a fase aguda e passaram para a fase crônica, nos demais a morte sobreveio entre o $27 .{ }^{\circ} \mathrm{e}$ - $31 .^{\circ}$ dia, quando a parasitemia já se achava em declínio. Estes resultados revelam uma taxa de letalidade de $70 \%$ para este lote.

Por outro lado, o índice de infecção, nos animais inoculados com $2 \times 10^{3}$ tripomastigotas sanguíneos da cepa Bolívia, foi de $100 \%$. O período pré-patente variou de 2 a 4 dias, com média de 3,03 dias para os camundongos inoculados pela via subcutânea e de 2,86 dias para os inoculados pela via intraperitoneal.
A parasitemia, embora variável, mostrou-se em média com os mesmos níveis para os animais inoculados por ambas as vias e a data em que ocorreu a parasitemia máxima variou entre o $17 .^{\circ}$ e o $21 .^{\circ}$ dia, para os dois lotes. Do animais inoculados pela via subcutânea, dezessete sobreviveram e nos demais a morte ocorreu em alguns casos coincidindo com o dia da parasitemia máxima e em outros quando a parasitemia se encontrava em declínio. A taxa de letalidade foi de $43,3 \%$. Para animais inoculados por via intraperitoneal, o comportamento foi semelhante, ou seja, sobreviveram dezoito animais e dos que morreram a morte sobreveio ou no pico da parasitemia ou na fase de declínio da mesma e a taxa de letalidade foi de $40 \%$.

A Tabela 2 mostra que o índice de infecção, para os animais inoculados com $2 \times 10^{4}$ tripomastigotas sanguíneos da cepa $\mathrm{Y}$, foi de $100 \%$, para ambos os lotes. O período pré-patente variou de 3 a 4 dias, com média de 3,5 dias para os inoculados por via subcutânea e 3,26 dias para os inoculados pela via intraperitoneal.

\section{TABELA 2}

Caracteres gerais da infecção das cepas $Y$ e Bolívia, através das vias subcutâneas e intraperitoneal, em camundongos inoculados com $2 \times 10^{4}$ formas sanguíneas do $T$. cruzi.

\begin{tabular}{|c|c|c|c|c|c|c|c|c|}
\hline \multirow{2}{*}{$\begin{array}{l}\text { Caracteres } \\
\text { da } \\
\text { Cepa/ infecção } \\
\text { via } \\
\text { Inoculação }\end{array}$} & \multirow[t]{2}{*}{$\begin{array}{c}\% \\
\text { de } \\
\text { infecção }\end{array}$} & \multicolumn{3}{|c|}{$\begin{array}{l}\text { Período } \\
\text { pré-patente }\end{array}$} & \multicolumn{2}{|c|}{$\begin{array}{c}\text { Limites } \\
\text { da variação } \\
\text { Parasitemia }\end{array}$} & \multirow[t]{2}{*}{$\begin{array}{c}\text { Duração } \\
\text { da } \\
\text { fase aguda }\end{array}$} & \multirow[t]{2}{*}{$\begin{array}{c}\text { Taxa } \\
\text { de } \\
\text { letalidade }\end{array}$} \\
\hline & & Min & Máx & Méd. & $\mathrm{N} 9 / \mathrm{mm}^{3}$ & Dia & & \\
\hline Y Sub. & 100,0 & 3 & 4 & 3,5 & $963-2.947$ & $89-10^{\circ}$ & $(-)$ & $100,0 \%$ \\
\hline$Y$ Intrap. & 100,0 & 3 & 4 & 3,26 & $959-2.947$ & $99-149$ & $16-19$ & $90,0 \%$ \\
\hline B. Sub. & 100,0 & 2 & 4 & 2,63 & $6.475-35.210$ & 159.219 & 28-31 & $70,0 \%$ \\
\hline B. Intrap. & 100,0 & 2 & 4 & 2,7 & $6.440-22.400$ & 159.219 & $26-30$ & $66,7 \%$ \\
\hline
\end{tabular}

(-) Indeterminada 
PINTO, F.H. et al. Estudo comparativo da infecção de camundongos, através da inoculação subcutânea e intraperitoneal, utilizando-se duas cepas do Trypanosoma cruzi. Rev. Saúde públ., S. Paulo, 20: 133-40, 1986.

A parasitemia variou de um animal para outro, entretanto, mostrou-se dentro dos mesmos níveis, nos dois lotes. O pico máximo da parasitemia ocorreu entre o $8 .^{\circ}$ e $10 .^{\circ}$ dia, para os camundongos inoculados pela via subcutânea, enquanto que para os inoculados por via intraperitoneal, variou entre o $9 .^{\circ}$ e $14 .^{\circ}$ dia, sendo portanto mais tardio nestes animais.

A taxa de letalidade foi de $100 \%$ para os animais inoculados pela via subcutânea è a morte ocorreu em alguns camundongos coincidindo com a parasitemia máxima enquanto outros morreram na fase de declínio da parasitemia. Para os animais inoculados por via intraperitoneal a taxa de letalidade foi de $90 \%$. Um fato que deve ser comentado é o de que a morte ocorreu nestes animais somente na fase de declínio da parasitemia.

Quando se comparam os resultados da via subcutânea e intraperitoneal nota-se que o índice de infecção foi de $100 \%$ entre os animais inoculados com $2 \times 10^{4}$, formas sanguíicolas da cepa Bolívia. $U$ período pré-patente variou de 2 a 4 dias, com média de 2,63 dias para os animais inoculados pela via subcutânea e de 2,7 dias para os inoculados através da via intraperitoneal. A parasitemia variou entre os animais de um mesmo lote e o máximo de parasitas ocorreu entre o $15 .^{\circ}$ e $21 .^{\circ}$ dia, nos dois lotes.

Dos animais inoculados através da via subcutânea, nove sobreviveram o que dá uma taxa de letalidade de $70 \%$, sendo que a morte ocorreu em alguns casos no acme da parasitemia e em outros na fase de declínio. No lote de animais inoculados intraperitonealmente, dez sobreviveram, resultando taxa de letalidade de $66,7 \%$. A semelhança do lote anterior os animais morreram ou no pico da parasitemia ou na fase de declínio da mesma.

Os resultados da Tabela 3 revelam um um índice de infecção de $100 \%$, um período pré-patente variando entre 3 a 4 dias, com média de 3,36 dias para os animais constituintes dos dois lotes. A parasitemia variou de um animal para outro, mesmo dentro de um dado lote, entretanto, mantém os mesmos níveis nos animais dos dois lotes. O pico da parasitemia ocorreu nos dois casos entre o $7 .^{\circ}$ e o $9 .^{\circ}$ dia e a taxa de letalidade foi de $100 \%$. Em ambos, a morte ocorreu, em alguns animais, no máximo de parasitemia e em outros na fase de declínio.

TABELA 3

Caracteres gerais da infecção das cepas $\mathrm{Y}$ e Bolívia, através das vias subcutâneas e intraperitoneal, em camundongos inoculados com $2 \times 10^{5}$ formas sanguíneas do $T$. cruzi.

\begin{tabular}{|c|c|c|c|c|c|c|c|c|}
\hline \multirow{2}{*}{$\begin{array}{l}\text { Cepa/ infecção } \\
\text { via } \\
\text { Inoculação }\end{array}$} & \multirow[t]{2}{*}{$\begin{array}{c}\% \\
\text { de } \\
\text { infecção }\end{array}$} & \multicolumn{3}{|c|}{$\begin{array}{l}\text { Período } \\
\text { pré-patente }\end{array}$} & \multicolumn{2}{|c|}{$\begin{array}{c}\text { Limites } \\
\text { da variação } \\
\text { Parasitemia }\end{array}$} & \multirow[t]{2}{*}{$\begin{array}{c}\text { Duração } \\
\text { da } \\
\text { fase aguda }\end{array}$} & \multirow[t]{2}{*}{$\begin{array}{c}\text { Taxa } \\
\text { de } \\
\text { letalidade }\end{array}$} \\
\hline & & Min. & Máx & Méd. & $\mathrm{N} 9 / \mathrm{mm}^{3}$ & Dia & & \\
\hline Y Sub. & 100,0 & 3 & 4 & 3,36 & $1.309 \cdot 4.382$ & 79.99 & $(-)$ & $100,0 \%$ \\
\hline Y Intrap. & 100,0 & 3 & 4 & 3,36 & $1.302-3.521$ & 79.99 & $(-)$ & $100,0 \%$ \\
\hline B. Sub. & 100,0 & 2 & 4 & 2,36 & $5.513-22.190$ & $149-249$ & $28-35$ & $83,4 \%$ \\
\hline B. Intrap. & 100,0 & 2 & 4 & 2,33 & $8.400-22.120$ & $149-219$ & $25-35$ & $83,4 \%$ \\
\hline
\end{tabular}

(-) Indeterminada 
PINTO, F.H. et al. Estudo comparativo da infecção de camundongos, através da inoculação $s$ ib. cutânea e intraperitoneal, utilizando-se duas cepas do Trypanosoma cruzi. Rev. Saúde púìl., S. Paulo, 20: 133-40, 1986.

Finalmente, comparando-se Bolívia subcutânea com Bolívia intraperitoneal nota-se que o índice de infecção foi de $100 \%$, o período pré-patente variou de 2 a 4 dias com média de 2,36 dias para os animais inoculados pela via subcutânea e 2,33 dias para os inoculados intraperitonealmente.

A parasitemia foi elevada e variou entre os animais, em ambos os lotes, ocorrendo o acme em dias variáveis, nos dois experimentos. A taxa de letalidade com o inoculo $2 \times 10^{5}$ tripomastigotas sangüíneos da cepa $Y$ foi de $100 \%$ e da cepa Bolívia foi de $83,4 \%$ sendo que, o dia da morte, em alguns casos, coincidiu com o da parasitemia máxima e em outros ocorreu quando a parasitemia já se encontrava em declínio.

\section{DISCUSSĀO}

Em hospedeiros vertebrados suscetíveis ao $T$. cruzi, o curso da infecção é típico, entretanto, é extremamente variável sofrendo influência de inúmeros fatores, ligados ao hospedeiro, ao meio ambiente e à população do parasita.

No que se refere à população do $T$. cruzi deve-se dar ênfase à variação intra-específica. Dados recentes mostraram "in vivo" o diferente tropismo dos parasitas Y (Mello e Brener ${ }^{15}$, 1978) e Bolívia (Ribeiro e col. ${ }^{19}, 1982$ ), sendo considerados de natureza macrofagotrópica os tripomastigotas $\mathrm{Y}$. Corroborando tais dados no hospedeiro vertebrado, estudos "in vitro" com macrófagos de camundongos normais inoculados com parasitas $Y$ (finos) e CL (largos), mostraram diferenças significantes, pois os tripomastigotas $Y$ infectam cerca de 20 vezes mais os macrófagos do que os parasitas CL (Alcântara e Brener ${ }^{1}$, 1978).

Existe diferença intra-específica do $T$. cruzi, com relação à velocidade de desaparecimento das formas sanguíneas, quando estas são inoculadas por via endovenosa, em animais normais, desapa- recendo os parasitas $\mathrm{Y}$ mais rapidamente do que os CL. Ribeiro e col. ${ }^{18}$ (1982) confirmaram estes resultados trabalhando com tripomastigotas finos e largos da cepa Bolívia do $T$. cruzi, observando que as formas delgadas desaparecem rapidamente da circulação, pois as mesmas pertencem ao grupo dos tripanossomos que mais facilmente penetram diferentes tipos de células "in vivo" e "in vitro" (revisto por Brener 7, 1977).

Em oposição, parasitas largos possuem capacidade de penetração em células reduzidas.

Como já foi referido anteriormente, Neal e MacHardy's (1977) inoculando camundongos normais, através das vias intraperitoneal e subcutânea, com a cepa $Y$ do $T$. cruzi concluiram que infecções mais uniformes e virulentas foram obtidas após inoculações subcutâneas. Segundo os autores, este fato se deve principalmente à resposta celular imediata, nas inoculações intraperitoneais.

Os resultados obtidos no presente trabalho revelam que nos experimentos em que se utilizou a cepa $Y$ existem algumas diferenças significantes, no que se refere ao curso da infecção, quando se utiliza a via subcutânea ou a via intraperitoneal para inoculação. Entretanto, isto não ocorre com a cepa Bolívia, pois os animais apresentaram o mesmo padrão de parasitemia e os demais caracteres morfo-biológicos equivalentes, quer se utilizasse a via de inoculação subcutânea quer a intraperitoneal.

Tal fato permite sugerir a existência de inter-relação entre os fatores via de inoculação (traduzida pela maior ou menor presença de macrófagos no sítio de inoculação) e morfologia das formas sanguíneas do $T$. cruzi (representada pela maior ou menor capacidade de penetração celular).

\section{AGRADECIMENTOS}

À Sra. Terezinha Aparecida Rissato e Garcia, pela colaboração técnica prestada. 
PINTO, F.H. et al. Estudo comparativo da infecçàio de camundongos, através da inoculação subcutânea e intraperitoneal, utilizando-se duas cepas do Trypanosoma cruzi. Rev. Saúde públ., S. Paulo, 20: 133-40, 1986.

PINTO. F.H. et al. [Comparative study of the behaviour of infection in mice, when inc. culated by intraperitoneal and subcutaneous methods. using two strains of Trupano. suma cruzi. Rev. Saúde públ., S. Paulo. $20: 133-40.1986$.

\begin{abstract}
By means of comparative studies of the infection of mice with $T$. cruzi using intraperitoneal and subcutaneous inoculation, it was concluded that more uniform and virulent infections are obtained after subcutaneous inoculation. This is due to an immediate cellular response, when intraperitoneal inoculations are used. With the aim of making comparative studies as between the two methods of inoculation, the intraperitoneal using two, morfologically distinct, strains of $T$. cruzi: $Y$ with predominance of thin forms and Bolivia with predominance of broad forms. White mice of approximately $18 \mathrm{~g}$ were required for these tests. The groups of animals received $2 \times 10^{3}, 2 \times 10^{4}$ and $2 \times 10^{5}$ trypanossomes per animal, and the course of the infection was subsequently observed. The results revealed that after subcutaneous inoculation when the $Y$ strain was used in the tests, some significant differences appear, with more virulent and uniform infections. However, these did not appear when the Bolivia strain was used, because the animals showed the same standard parasitemy and other morpho-biological features, whether by subcutaneous or intraperitoneal inoculation. This incident suggests the existence of interrelation between the factors: method of inoculation represented by a greater or lesser presence of macrophages in the inoculated area, and the morphology of the blood forms represented by a greater or lesser capacity for cellular penetration.
\end{abstract}

UNITERMS: Trypanosoma cruzi. Mice, experimental infection. Macrophages, parasitology. Infections, subcutaneous. Infections, intraperitoneal,

\title{
REFERENCIAS BIBLIOGRÁFICAS
}

1. ALCÂNTARA, A. \& BRENER, Z. The "in vitro" interaction of Trypanosoma cruzi bloodstream forms and mouse peritoneal macrophages. Acta trop., 35: 209.19, 1978.

2. ANDRADE, S.G.; CARVALHO, M.L. \& FIGUEIRA, R.M. Caracterização morfológica e histo-patológica de diferentes cepas do Trypanosoma cruzi. Gaz. méd. Bahia, 70: 32-42, 1970.

3. BELDA NETO, F.M. Estudo sobre a existência de correlação entre os dados biométricos e o grau de patogenicidade de amostras humanas do Trypanosoma cruzi Chagas, 1909. Rev. Soc. bras. Med. trop., 8: 27-36, 1974.

4. BRENER, Z. Therapeutic activity and criterion of cure on mice experimentally infected with Trypanosoma cruzi. Rev. Inst. Med. trop. S. Paulo, 4: 389. 96, 1962.

5. BRENER, Z. Comparative studies of different strains of Trypanosoma cruzi. Ann. trop. Med. Parasit., 59: 19-26, 1965.

6. BRENER, $Z$. The behaviour of slender and stout forms of Trypanosoma cruzi in the bloodstream of normal and immunemice. Ann. trop. Med. Parasit., 63: 215-20, 1969.

7. BRENER, $Z$. Intraspecific variation in "Trypanosoma cruzi": two tipes of parasite populations presenting distinct characteristics. Washington, D.C., Pan American Health Organization, 1977. p. 11-21. (PAHO . Scient Publ., 347).

8. BRENER, Z. \& CHIARI, E. Variações morfológicas observadas em diferentes amostras de Trypanosoma cruzi. Rev. Inst. Med. trop. S. Paulo, 5: 220-7, 1963.

9. CHAGAS, C. Nova tripanosomiase humana. Estudos sobre a morfologia e o ciclo evolutivo do Schizotrypanum cruzi, n.gen., n.sp., agente etiológico de nova entidade mórbida do homem. Mem. Inst. Oswaldo Cruz, 1: 159-218, 1909.

10. COURA, J.R.; FERREIRA, L.F.; RUBENS, J.; PEREIRA, N.C. \& SILVA, J.R. Tripanosoma do "complexo cruzi" em reservatório silvestre do Estado da Guanabara. Estudo de sua patogenicidade. Rev. Inst. Med. trop. S. Paulo, 8: 134-8, 1966. 
PINTO, F.H. et al. Estudo comparativo da infecção de camundongos, através da inoculação sub. cutânea e intraperitoneal, utilizando-se duas cepas do Trypanosoma cruzi. Rev. Saúde públ., S. Paulo, 20: 133-40, 1986.

11. DVORAK, J.A. \& SHMUNIS, G.A. Trypanosoma cruzi: interaction with mouse peritoneal macrophages. Exper. $\mathrm{Pa}$ rasit., 32: 289-300, 1972.

12. FERRIOLLI FILHO, F.: BARRETTO M.P. \& CARVALHEIRO, J.R. Estudo sobre reservatórios e vectores silvestres do Trypanosoma cruzi. XXIV - Variação dos dados biométricos obtidos em amostras do $T$. cruzi isoladas de casos humanos de doença de Chagas. Rev. bras, med. trop., 2: 1-8, 1968.

13. HOFF, R. Killing in vitro of Trypanosoma cruzi by mocrophages from mice immunized with $T$. cruzi or BCG, and absence of cross-immunity on challenge in vivo. $J$. exper. Med., 142: 299 . $311,1975$.

14. KIERSZENBAUM, F.; KNECHT, R.; BUDZKO, D.B. \& PIZZIMENTI, $M$. C. Phagocytosis: a defense mechanism against infection with Trypanosoma cruzi. J. Immunol., 112: 1839-44. 1974.

15. MELO, R.C. \& BRENER, Z. Tissue tropism of different Trypanosoma cruzi strains. J. Parasit., 64: 475-82, 1978.

16. NEAL, R.A. \& MacHARDY, N. Comparasion of infectivity of Trypanosoma cruzi blood stream trypomastigotas and metacyclic trypomastigotas from Rhodnius prolixus. Acta. trop., 34: 79-85, 1977.

17. NOGUEIRA, N. \& COHN, L. Trypanosoma cruzi: mechanism of entry and intracellular fate in mammalian cells. J. exper. Med., 143: 1402-20, 1976.

18. RIBEIRO, R.D.; BELDA NETO, F.M. \& FERRIOLLI FILHO, F. Estudo do comportamento de tripomastigotas sanguíícolas de subamostras do Trypanosoma cruzi inoculados endovenosamente em camundongos normais e imunes. Rev. bras. Biol., 42: 79-83, 1982.

19. RIBEIRO, R.D.; FERRIOLLI FILHO, F. \& BELDA NETO, F.M. Comporta. mento de subamostras do Trypanosoma cruzi em hospedeiros vertebrados e invertebrados. Rev. bras. Biol., 42: 51-4, 1982.

20. SILVA, L.H.P. \& NUSSENZWEIG, V. Sobre uma cepa de Trypanosoma cruzi altamente virulenta para o camundongo branco. Fol. clin. biol., 20: 191 . 208, 1953.

Recebido para publicaşão em 03/10/1985

Aprovado para publicação em 06/01/1986 